\title{
Artan Mobil Teknoloji Kullanımının Yol Açtığı Ağrı Sendromu: "Text
}

\author{
Neck"
}

Pain Syndrome That Occurs with Increased Usage of Mobile Technology: "Text

Neck"

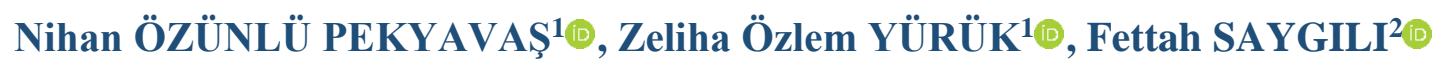

${ }^{1}$ Başkent Üniversitesi Sağlık Bilimleri Fakültesi, Fizyoterapi ve Rehabilitasyon Bölümü, Ankara, Türkiye

${ }^{2}$ Gazi Üniversitesi Sağlık Bilimleri Fakültesi, Fizyoterapi ve Rehabilitasyon Bölümü, Ankara, Türkiye

ÖZ

\begin{abstract}
Akıllı telefon ve tabletler iletişim, ulaşım, eğlence, eğitim ve güvenlik gibi pek çok amaçla kullanılan ve giderek yaygınlaşan mobil teknolojik cihazlardır. Toplumun her kesimi tarafindan kullanılmakla birlikte özellikle çocuklar ve gençlerin akıllı telefon ve tabletler ile çok uzun süre geçirdikleri gösterilmiştir. Mobil teknoloji kullanımın artması ile birlikte kas iskelet sistemi ağrıları, uykusuzluk, konsantrasyon güçlüğü ve yorgunluk gibi çeşitli semptomlar ortaya çıkmaktadır. "Text neck” tanımı ilk kez Dr. Dean L. Fishman tarafindan uzun süre akıllı telefon ve tablet kullananlarda boyun, baş ve omuz ağrısı ve üst ekstremitelerde uyuşma problemi olarak tanımlanmıştır. Mobil cihazları kullanırken uzun süre baş ve kolların önde olduğu kifotik bu postürün erken artrit başlangıcı ve disk dejenerasyonu için potansiyel risk oluşturduğu düşünülmektedir. "Text neck"in boyun ağrısı, sırt ağrısı, omuz ağrısı, baş ağrısı, uykusuzluk, ellerde karıncalanma ve uyuşma gibi çeşitli semptomları bulunmaktadır. "Text neck" için belli tanı kriterleri olmamakla birlikte bazı araştırmacılar baş ve boyun postürünün değerlendirilmesi için görsel yöntemler geliştirmişlerdir. "Text neck" için öncelikle koruyucu fizyoterapi yaklaşımları önerilebilir. Semptomların varlığı durumunda ise tedavi edici fizyoterapi teknikleri uygulanabilir. Koruyucu ve tedaviye yönelik fizyoterapi yaklaşımları konusunda çok az sayıda çalışma bulunmaktadır. Bu çalışmalarda postür eğitimi, farkındalığın artırılması, ergonomik düzenlemeler ve egzersiz programları ön plana çıkmaktadır. Bu derlemede "text neck" sendromuna neden olan faktörler, görülen semptomlar, değerlendirme yöntemleri ve tedavi yaklaşımları ele alınarak güncel literatür ile birlikte tartışılmıştır.
\end{abstract}

Anahtar Kelimeler: Ağrı, Akıllı Telefon, Egzersiz, Postür.

ABSTRACT

Smartphones and tablets are mobile technological devices that are used for many purposes such as communication, transportation, entertainment, education, and security. Although it is used by all age groups of the community, especially children and adolescents spend a long time with smartphones and tablets. With the increasing use of mobile technology, various symptoms such as musculoskeletal pain, insomnia, difficulty in concentrating, and fatigue appear. The definition of "text neck" is the firstly described by Dr. Dean L. Fishman as has a problem of the neck, head and shoulder pain, and numbness in the upper extremities who use smartphones and tablets for a long time. This kyphotic posture, which the head and arms are at the front for a long time while using mobile devices, is thought to pose a potential risk for early arthritis onset and disc degeneration. "Text neck" has various symptoms such as neck pain, back pain, shoulder pain, headache, insomnia, tingling, and numbness at the hands. Although there are no specific diagnostic criteria for "text neck", some researchers have developed photographic methods to evaluate the head and neck posture. Preventive physiotherapy approaches can be suggested for "text neck". In case of symptoms, therapeutic physiotherapy techniques can be applied. There are very few studies on preventive and therapeutic physiotherapy approaches. In these studies, postural education, to increase awareness, ergonomic design, and exercise programs become prominent. In this review, factors that cause "text neck" syndrome, symptoms, assessment methods, and treatment approaches are discussed with the literature.

Key Words: Pain, Smartphone, Exercise, Posture.

Sorumlu Yazar: Zeliha Özlem YÜRÜK

Başkent Üniversitesi Sağlık Bilimleri Fakültesi, Fizyoterapi ve Rehabilitasyon Bölümü, Fatih Sultan Mehmet Mahallesi, Eskişehir Yolu 18.km. 06790 Bağlıca, Ankara, Türkiye.

bastug@baskent.edu.tr

Geliş Tarihi: 02.04.2020 - Kabul Tarihi: 10.07.2020 


\section{GIiRiș}

Akıllı telefon ve tabletler iletişim, ulaşım, eğlence, eğitim ve güvenlik gibi pek çok amaçla kullanılan ve giderek yaygınlaşan mobil teknolojik cihazlardır (1). Bireylerin haftada ortalama 20 saatlerini akıllı telefon veya tablet başında harcadıkları bilinmektedir. Akıllı tablet ve telefon kullanımı özellikle çocuklar ve gençler arasında çok yaygındır. Bir çalışmada, çocuk ve gençlerin günde 5-7 saat arasını akıllı telefon kullanarak geçirdikleri ve bu sürenin yılda ortalama 1825 ile 2555 saate denk geldiği gösterilmiştir (2). Bir başka çalışmada ise, 292 üniversite öğrencisinin \%58,4'ünün ev ortamında ve \%40'ının oturma pozisyonunda akıllı telefon kullandığ ve \%80'ininden fazlasının günde en az iki saatini akıllı telefon ile geçirdiği belirtilmiştir. Ayrıca akıllı telefon veya tablet ile geçirilen bu sürenin büyük kısmının mesajlaşma için kullanıldığg görülmüştür (3). Gittikçe artan mobil teknoloji kullanımı başta kas iskelet sistemi problemleri olmak üzere uykusuzluk, konsantrasyon güçlüğü ve yorgunluk gibi çeşitli semptomlara yol açmaktadır. "Text neck" uzun süre ak1llı telefon ve tablet kullanan bireylerde artmış baş ve boyun fleksiyon postürü nedeniyle görülen bir kas iskelet sistemi problemidir. İlk kez Dr. Dean L. Fishman tarafindan tanımlanmıştır. Boyun, sırt, omuz ve baş ağrısı, uykusuzluk, ellerde karıncalanma ve uyuşmaya yol açmaktadır. Literatürde "text neck" probleminin farklı toplumlarda görülme sıklığının arttığını gösteren çalışmalar bulunmaktadır. Bununla birlikte değerlendirme yöntemleri ve fizyoterapi ile ilgili çeşitli öneriler yer almaktadır. $\mathrm{Bu}$ derleme "text neck"e yol açan faktörleri, neden olduğu semptomları, değerlendirme ve tedavi yöntemlerini incelemek amacıyla hazırlanmıştır.

Literatür taraması öncesinde tarama yapılacak veri tabanları, anahtar kelimeler ve eş anlamlıları belirlendi. Taramalar yapılırken yıl sınırlaması olmaksızın İngilizce dili ile yazılmış çalışmalar ele alındı. EBSCO Medline, Ovid (Wolters Kluwer), PubMed ve Scopus (Elsevier) veri tabanlarında tarama yapıldı. Tarama yapılırken "smartphone", "text neck", "pain" ve "posture" anahtar kelimeleri kullanıldı. EBSCO Medline (13 makale), Ovid (Wolters Kluwer) (8 makale), Pubmed (401 makale) ve Scopus (Elsevier) (26 makale) veri tabanlarından toplam 448 çalışmaya ulaşıldı. Araştırmaların başlıkları ile özetleri iki araştırmacı tarafından gözden geçirildi ve aynı çalışmalar ile derleme konusu ile ilgili olmayan çalışmalar dışlandı. Sonuç olarak derleme için 24 çalışma incelendi.

\section{Artan Mobil Teknoloji Kullanımının Yol Açtığı Problemler}

Uzun süre masa başı ve bilgisayar ekranı karşısında çalışan bireylerin çeşitli kas iskelet sistemi problemleri yaşadıkları bilinmektedir. Literatürde bu problemleri önleme veya tedaviye yönelik pek çok çalışma bulunmaktadır $(4,5)$. Akıllı telefon ve tabletlerin kullanımı sırasında ise bilgisayar kullanımından farklı olarak uzun süreli ve tekrarlı baş ve boyun fleksiyon postürü ortaya çıkmaktadır. Bu pozisyon alt servikal bölgede lordozu azaltır, üst torakal bölgede ise kifozu artırır (6). Uygun olmayan bu postür; servikal bölge ve çevresinde ağrı, yorgunluk, azalmış fizyolojik fonksiyon ve günlük yaşamda problemlere yol açabilmektedir (3). Bir diğer problem ise; el ve parmaklarda açığa çıkan tekrarlayıcı hareketlerdir (7). Özellikle hızlı mesaj yazma alışkanlığı el yapılarında strese yol açmakta, ağrı ve kavrama kuvvetinde kayba neden olabilmektedir (1).

Uzun süreli akıllı telefon veya tablet kullanımının anksiyete ve stres düzeylerinin artmasına ve uyku problemlerine yol açtığı da bilinmektedir. Lemola ve ark. (2015), gençlerde mobil teknoloji kullanımının uykusuzluk, yorgunluk ve enerji düşüklüğüne neden olduğunu 
göstermişlerdir (8). Zheng ve ark. (2014)'ın 7102 genç birey üzerinde yürüttükleri bir çalışmada ise, uzun süreli mobil cihaz kullanımının dikkat problemlerine ve hafıza güçlüklerine yol açabileceği de gösterilmiştir (9). Özetle mobil cihazların uzun süre kullanımının yol açtığ problemler şu şekilde sıralanabilir $(1,8-10)$ :

- Boyun ağrisi

- Omuz ağrisi

- Baş ağrıs1

- Başparmak aşırı kullanım sendromu ("blackberry thumb")

- Temporamandibular eklem fonksiyon bozukluğu

- Anksiyete

- Konsantrasyon güçlüğü

- Uykusuzluk

- Hafiza problemleri

- Depresyon

- Göz yorgunluğu

\section{Artan Mobil Teknoloji Kullanımın Yol Açtığı Bir Problem: “Text Neck”}

Servikal bölgede ağrıya neden olan önemli risk faktörlerinden biri tekrarlı ve uzun süreli baş ve boyun fleksiyon postürüdür. Bu postür ligament, tendon, kas ve kemik yapılar üzerinde mekanik strese yol açmaktadır. Sonuçta erken artrit başlangıcı, disk dejenerasyonu ve baş ağrısı için potansiyel risk oluşturmaktadır (1). Son dönemlerde gençlerin baş ve boyun ağrısı şikâyeti ile bir uzmana başvurma oranı artmıştır. Bu bireylerin çoğunda kifotik postür hakimdir ve Xray veya manyetik rezonans görüntüleme tekniklerinin sonuçları normal çıkmaktadır. $\mathrm{Bu}$ bireylerin çoğunun ortak noktası uzun süre mobil cihaz kullanımıdır (11).

"Text neck" tanımı ilk kez Dr. Dean L. Fishman tarafindan uzun süre akıllı telefon ve tablet kullananlarda boyun, baş ve omuz ağrısı ve üst ekstremitelerde uyuşma problemi olarak tanımlanmıştır $(1,11)$. Mobil cihazları kullanırken baş ve kolların önde olduğu kifotik bu postür "text neck" veya "turtle neck" olarak adlandırılmıştır. "Text neck"in altı temel semptomu bulunmaktadır (1): boyun ağrıs1, sırt ağrıs1, omuz ağrıs1, baş ağrıs1, uykusuzluk, ellerde karıncalanma ve uyuşma.

Han ve ark. (2018), 31 üniversite öğrencisinde günlük akıllı telefon kullanım süresi ve başın anterior tilt açısını değerlendirdikleri çalışmalarında, ögrencilerin günlük ortalama 125 dakika akıllı telefon kullandıklarını ve ortalama 300 anterior baş tilti yaptıklarını bulmuşlardır. Öğrencilerin telefon kullanmadıkları ve diğer aktivitelerle uğraştıkları zamanlarda ise başın anterior tilt açısının en fazla 200 olduğu görülmüştür (12). Başın anterior tilti arttıkça servikal bölgeye binen yük miktarı da artmaktadır. Başın nötral pozisyonunda servikal bölgede taşınan yük miktarı ortalama 4.5-5.5 kg'lık başın kendi ağırlığıdır. Boynun 150 fleksiyonu ile bu yükün 12.25 kg'a, 300'de ise $13.61 \mathrm{~kg}$ 'a ulaştığ 1 tahmin edilmektedir. Çocuklar daha fazla risk altındadır çünkü baş ağırlıkları vücutlarına oranla daha fazladır (13).

Berolo ve ark. (2011) mobil cihazlar kullanan bireylerde boyun, omuz ve başparmak ağrısının sık görüldüğünü belirtmişlerdir. Kanada' da 140 birey üzerinde yapılan çalışmada \%68 oranında boyun ağrısının, \%46-52 oranında ise omuz ağrısının görüldüğü bildirilmiştir (14). Çin'de ise uzun süreli mobil cihaz kullanan 2575 bireyde \%40 oranında boyun ve omuz ağrısının görüldüğü rapor edilmiştir (15). Xie ve ark. (2016) gün içinde uzun süreli akıllı telefon kullanan ve boyun ağrısı şikâyeti olan ve olmayan bireylerde servikal bölgede kas aktivitesini değerlendirmişlerdir (16). Cihaz kullanımı sırasında kas aktivitesini elektromiyografik olarak ölçmüşlerdir. Sonuçta, ağrı şikâyeti olan bireylerde kas aktivitesinin daha yüksek olduğunu bulmuşlardır. Ayrıca tek elle cihaz kullanan bireylerde, çift elle kullananlara göre yine kas 
aktivitesinin daha yüksek olduğunu belirlemişlerdir. Portelli ve Reid (2018) ise, "text neck" olan bireylerde servikal propriyosepsiyon duyusunda azalma olduğunu bulmuşlardır (17).

Bununla birlikte mobil cihaz kullanımı ile boyun ağrısı arasında ilişki olmadığını savunan çalışmalar da vardır. Bu çalışmalar genellikle boyun ağrısının hatalı biyomekanikten kaynaklanmadığını, değișen ağrı mekanizmalarına bağlı olarak ortaya çıktığını savunmaktadırlar (18). Damasceno ve ark. (2018), 18-21 yaş arası 150 bireyde mobil cihaz kullanımı ile boyun ağrısının ilişkili olmadığını savunmuşlardır (19).

Her ne kadar çalışmalar farklı sonuçlar gösterse de son yıllarda "text neck" global bir problem haline gelmekte ve bu konudaki literatür hızla gelişmektedir. $\mathrm{Bu}$ nedenle fizyoterapistler daha çok gençlerde ortaya çıkan ve ileri yaşlarda potansiyel artrit ve disk dejenerasyonu gibi problemlere yol açabilecek bu sendromun farkında olmalı ve doğru değerlendirme, önleme ve etkili tedavi yöntemlerini uygulayabilmelidir (20).

\section{Değerlendirme Yöntemleri}

"Text neck" ile ilgili en önemli problem henüz tanı kriterlerinin tam olarak belirlenememiş olmasıdır. Tipik baş önde kifotik postürün görüldüğü bireylerin çoğunda X-ray veya manyetik rezonans görüntüleme tekniklerinin sonuçlarının normal olduğu belirtilmiştir (11). Vijayakumar ve ark. (2018) günde üç saatten fazla mobil cihaz kullanmak ve boyun ağrısı, sırt ağrısı, omuz ağrısı, baş ağrısı, uykusuzluk, ellerde karıncalanma ve uyuşma olmak üzere altı temel semptomdan üçünün bulunmasının "text neck" olarak kabul edilebileceğini belirtmişlerdir (1). Burada en önemli noktalardan biri gün içinde mobil cihazın kullanım süresinin uzun olmasidır.

Damasceno ve ark. (2018) "text neck" postürünü tanımlayabilmek için bir özel görsel yöntem geliştirmişlerdir. $\mathrm{Bu}$ yöntemde hastalara dört farklı fotoğraf gösterilerek günlük yaşamda en çok hangi postürde mobil cihaz kullandıkları sorulmuştur. İlk iki fotoğraf dar açılarda boyun fleksiyonu yapan bir bireye aittir. Fotoğraflardan üç ve dördüncüsü ise geniş açıda boyun fleksiyonunu içeren yüksek riskli postürleri göstermektedir. Bu değerlendirme yönteminde bireyin kendi kendini değerlendirmesi beklenir. Bu yöntemin güvenilir olduğu gösterilmiştir (19). Meziat-Filho ve ark. (2016) ise, lateral plandan çekilen fotoğraf yöntemi ile değerlendirme yapmışlardır. Bireylere bir duvarın önünde sabit noktada ayakta en rahat oldukları pozisyonda durmaları istenmiş ve fotoğrafları çekilmiştir. İki deneyimli değerlendirici bireylerin postürlerini normal, kabul edilebilir, uygun olmayan ve çok kötü olarak değerlendirmişlerdir. Her iki çalışmada da akıllı telefon kullanım süresi sorgulanmış ve "text neck"de görülen postüral anormalliklerin tanımlanmasına çalışılmıştır (21).

"Text neck"e özel değerlendirmeler dışında literatürde çeşitli değerlendirme yöntemleri de kullanılmıştır $(1,22,23)$ :

- Ağr1

- Postür analizi

- Kavrama kuvveti

- Eklem hareket açıklığ

- Kuvvet basınçlı biofeedback cihazı

- Elektromiyografi

- Akıllı Telefon Bağımlılık Skalası

- Boyun Özürlülük Ölçeği

\section{Fizyoterapi}

Günümüzde "text neck" problemi yaşayan bireylerin sayısı artmaktadır. Uzun dönemde bu sendromun erken yaşlarda artrit, disk dejenerasyonu ve temporamandibular eklem fonksiyon 
bozukluğuna yol açabileceği öngörülmektedir. Bu nedenle bu problem için öncelikle koruyucu fizyoterapi yaklaşımları önerilmeli; semptomların varlığı durumunda uygun tedavi yöntemleri seçilmelidir (24).

"Text neck" problemi olan bireylerde cihaz başında harcanan süre ile ağrı şiddeti ilişkili bulunmuştur (9). Dolayısıyla tedavide ilk adım mobil cihaz kullanım süresinin düzenlenmesidir. Postüral farkındalık sağlamak ve hatalı postürün azaltılması bir diğer önemli fizyoterapi yöntemidir (24). Lee ve ark. (2015), 18 bireyde mesajlaşma, web tarama, video izleme gibi aktiviteler sırasında boyun postürünü üç boyutlu olarak inceledikleri çalışmalarında en çok oturma pozisyonunda mesajlaşma sırasında boyun fleksiyon açısının arttığını bulmuşlardır (25). Vijayakumar ve ark. (2018) ise, 18-25 yaş arası günde en az üç saat mobil cihaz kullanan bireyler için postüral koreksiyonu içeren fizyoterapi yöntemlerinin önemli olduğunu vurgulamışladır (1). Bu noktada hasta eğitimi büyük önem kazanmaktadır. Hem cihaz kullanım süresinin hem de postürün önemi örnekler ile anlatılmalı, özellikle oturma pozisyonunda doğru postürün önemi vurgulanmalıdır.

Bilgisayar kullanımında ergonomik düzenlemelerin postür üzerinde etkili olduğu bilinmektedir (4,5). Ancak mobil cihaz kullanımında ergonomik düzenlemelerin etkisi ile ilgili çalışmalar kısıtlıdır. Syamala ve ark. (2018) 20 genç erişkinde yaptıkları çalışmada laboratuar ortamında mobil cihaz kullanımı sırasında boyun ve üst ekstremiteler üzerindeki yüklenmeyi ne ölçüde etkilediğini kinematik ve elektromiyografik olarak değerlendirmişlerdir. Sonuçta; boyun fleksiyon açısının kaslar üzerinde önemli strese yol açtığı, kol ve sirt desteği olan sandalyelerin bu stresi azalttığını belirtmişlerdir (5). Mobil cihaz kullananlarda cihazın göz seviyesinde tutulması ve kol desteğinin kullanılması, cihazın her iki elle tutulması ve her iki başparmak ile kullanılması önerilebilir (11).

Postür ve ağnı probleminin hâkim olduğu bu tabloda hem koruyucu hem de tedavi amacıyla egzersiz programlarının uygulanması gereklidir (11). Egzersiz programının başlangıcında temel germe ve eklem hareket açıklığı egzersizleri ısınma amacıyla verilebilir (26). Egzersiz programında üst ekstremite, boyun ve üst gövde kaslarına yönelik germe ve kuvvetlendirme egzersizleri yer almalıdır. Kuvvetlendirme egzersizleri izometrik veya serbest ağırlıklar ile düzenlenebilir. Postür egzersizleri ve skapular egzersizler programa dahil edilmelidir. Ayrıca "core" stabilizasyon egzersizleri de öğretilebilir. Ağrı için mobilizasyon gibi tekniklerden yararlanılabilir (26,27). Abdehameed ve Abdel-Aziem (2016) 100 üniversite öğrencisinde yaptıkları çalışmada bir gruba kuvvetlendirme, germe ve postür egzersizlerinden oluşan fizyoterapi programını verirken, kontrol grubuna herhangi bir uygulama yapmamışlardır. Sonuçta; 12 haftalık eğitimin kavrama kuvvetini geliştirdiğini ve üst ekstremite semptomlarını azalttığını belirlemişlerdir (26). Bu çalışmalar dışında önleyici veya tedavi edici fizyoterapi yöntemlerinin etkisini inceleyen çalışmalar çok sınırlıdır.

Sonuç olarak; akıllı telefon ve tablet gibi artan mobil teknolojik cihazların uzun süreli kullanımı kas iskelet sistemi başta olmak üzere pek çok probleme yol açmaktadır. Bu problemlerden biri de "text neck”tir. “Text neck"in görülme sıklı̆̆ı ve semptomları konusunda çeşitli çalışmalar bulunmaktadır. Ayrıca özel postüral değerlendirme yöntemleri geliştirilmektedir. "Text neck" için koruyucu ve tedaviye yönelik fizyoterapi yaklaşımları konusunda ise çok az sayıda çalışma bulunmaktadır. $\mathrm{Bu}$ çalışmalarda bireylerin bilgilendirilmesi, postüral farkındalık, ergonomik düzenlemeler ve egzersiz eğitimi ön plana çıkmaktadır. Günümüzde özellikle çocuk ve gençlerde artan mobil teknoloji kullanımının potansiyel riskleri göz önüne alınarak bu konuda daha detaylı çalışmalara ihtiyaç vardır. 


\section{KAYNAKLAR}

1. Vijayakumar, M., Mujumdar, S., \& Dehadrai, A. (2018). Assessment of co-morbid factors associated with text-neck syndrome among mobile phone users. International Journal of Scientific Research in Science and Technology, 4(9), 38-46.

2. Fares, J., Fares, M. Y., \& Fares, Y. (2017). Musculoskeletal neck pain in children and adolescents: risk factors and complications. Surg Neurol Int, 8, 72.

3. Kim, H. J., \& Kim, J. S. (2015). The relationship between smartphone use and subjective musculoskeletal symptoms and university students. J Phys Ther Sci, 27(3), 575-579.

4. Szeto, G. P., \& Lee, R. (2002). An ergonomic evaluation comparing desktop, notebook, and subnotebook computers. Arch Phys Med Rehabil, 83(4), 527-532.

5. Syamala, K. R., Ailneni, R. C., Kim, J. H., \& Hwang, J. (2018). Armrests and back support reduced biomechanical loading in the neck and upper extremities during mobile phone use. Appl Ergon, 73, 48-54.

6. Kim, J. H, Kim, J. G., Do, K. S., \& Yim, J. (2016). The effect of applying a headweight device on cervical angle and pain of neck muscles. Phys Ther Rehabil Sci, 5(2), 101105.

7. Shah, P. P., \& Sheth, M. S. (2018). Correlation of smartphone use addiction with text neck syndrome and sms thumb in physiotherapy students. International Journal of Community Medicine and Public Health, 5(6), 2512-2516.

8. Lemola, S., Perkinson-Gloor, N., Brand, S., Dewald-Kauffman, J. F. \& Grob, A. (2015). Adolescents electronic media use at night, sleep disturbances and depressive symptoms in the smartphone age. $J$ Youth Adolesc, 44(2), 405-418.

9. Zheng, F., Gao, P., He, M., Li, M., Wang, C., \& Zeng, Q., et al. (2014). Association between mobile phone use and inattention in 7102 Chinese adolescents: a populationbased cross-sectional study. BMC Public Health, 14, 1022.

10. Alzarea, B. K., \& Patil, S. R. (2015). Mobile phone head and neck pain syndrome: proposal of a new entity. Oral Health and Dental Management, 14(5), 313-317.

11. Cuellar, J. M., \& Lanman, T. H. (2017). "Text neck" an epidemic of the modern era of cell phones? Spine J, 17(6), 901-902.

12. Han, H., Lee, S., \& Shin, G. (2018). Naturalistic data collection of head posture during smartphone use. Ergonomics, 62(3), 444-448.

13. Hansraj, K. K. (2014). Assessment of stresses in the cervical spine caused by posture and position of the head. Surg Technol Int, 25, 277-279.

14. Berolo, S., Wells, R. P., \& Amick, B. C. (2011). Musculoskeletal symptoms among mobile hand-held device users and their relationship to device use: a preliminary study in a canadian university population. Appl Ergon, 42(2), 371-378.

15. Shan, Z., Deng, G., Li, J., Li, Y., Zhang, Y., \& Zhao, Q. (2013). Correlational analysis of neck/shoulder pain and low back pain with the use of digital products, physical activity an pschological status among adolescents in Shanghai. Plos One, 8(10), 78-109.

16. Xie, Y., Szetoa, G. P. Y., Daia, J., \& Madeleine, P. (2016). A comparison of muscle activity in using touchscreen smartphone among young people with and without chronic neck-shoulder pain. Ergonomics, 59(1), 61-72.

17. Portelli, A., \& Reid, S. A. (2018). Cervical proprioception in a young population who spend long periods on mobile devices: a 2-group comparative observational study. $J$ Manipulative Physiol Ther, 41(2), 123-128.

18. Richards, K. V., Beales, D. J., Smith, A. J., O'Sullivan, P. B., \& Straker, L. M. (2016) Neck posture clusters and their association with biopsychosocial factors and neck pain in Australian adolescents. Phys Ther, 96(10), 1576-1587.

19. Damasceno, G. M., Sá Ferreira, A., Nogueira, L. A. C., Reis, F. J., Andrade, I. C. S., \& 
Meziat-Filho, N. (2018). Text neck and neck pain in 18-21-year-old young adults. Eur Spine J, 27(6), 1249-1254.

20. Al-Gharabawi B. (2017). Text neck syndrome: a new concern for physical therapists worldwide. EC Orthopaedics, 8(3), 89-91.

21. Meziat-Filho, N., Mendonça, R., Pezolato, A., Reis, F. J., \& Calazans Nogueira, L. A. (2016). Reproducibility of the low back clinical postural grouping in adolescents. $J$ Bodyw Mov Ther, 20(2), 265-269.

22. Kwon, M., Lee J. Y., Won, W. Y., Park, J. W., Min, J. A., \& Hahn, C. (2013). Development and validation of a Smartphone Addiction Scale (SAS). PLoS One, 8(2), e56936.

23. Vernon, H., \& Mior, S. (1991). The neck disability index: a study of reliability and validity. J Manipulative Physiol Ther, 14(7), 409-415.

24. Neupane, S., Ifthikar Ali, U. T., \& Mathew, A. (2017). Text neck syndrome-systematic review. Imperial Journal of Interdisciplinary Research, 3(7), 141-148.

25. Lee, S., Kang, H., \& Shin, G. (2015). Head flexion angle while using a smartphone. Ergonomics, 58(2), 22-26.

26. Abdelhameed, A. A., \& Abdel-Aziem, A. A. (2016). Exercise training and postural correction improve upper extremity symptoms among touchscreen smartphone users. Hong Kong Physiotherapy Journal, 35(2), 37-44.

27. Thiyagarajan, S., \& Telegbal, S. V. (2015). Text Neck: is it a new term for physiotherapist? Indian Journal of Medical \& Health Sciences, 2(2), 119-121. 